\title{
The Role of Support Groups in the Management of Depression amongst People Living with HIV at Regional Hospital of Bamenda
}

\author{
Ayina Lionel Wamia1 (D), Ngachangong Victorine ${ }^{2 *}$ \\ ${ }^{1}$ St. Elizabeth Catholic General Hospital/Cardiac Center Shisong \\ ${ }^{2}$ Saint Louis University Institute of Health and Biomedical Sciences, Bamenda, Cameroon \\ Email: ayinalionel@gmail.com, *prettyvicky84@yahoo.com
}

How to cite this paper: Wamia, A. L., \& Victorine, N. (2019). The Role of Support Groups in the Management of Depression amongst People Living with HIV at Regional Hospital of Bamenda. Open Journal of Depression, 8, 71-84.

https://doi.org/10.4236/ojd.2019.84008

Received: November 9, 2019

Accepted: November 27, 2019

Published: November 30, 2019

Copyright $\odot 2019$ by author(s) and Scientific Research Publishing Inc. This work is licensed under the Creative Commons Attribution International License (CC BY 4.0).

http://creativecommons.org/licenses/by/4.0/

\begin{abstract}
Depression is the most common neuropsychiatric mental condition found among people living with HIV (PLHIV). Despite its high prevalence, depression remains under diagnosed amongst PLHIV, and determining its prevalence is very cumbersome. As a mental condition, it has been associated with increased comorbidity, non-adherence to HAART, suicidal attempts, unsafe sex practice, just to name a few. Support groups have been shown to play an important role in the improvement of the quality of life of PLHIV and could be a means of managing depressive symptoms that arise in their lifetime. The aim of this research was to assess the role of support groups in the management of depression amongst PLHIV at the Bamenda Regional Hospital (BRH). This was a hospital based, observational cross sectional and descriptive study used to gather information from, one hundred and fifty two (152) HIV positive patients sticking to appointments at the treatment centre of BRH. The patient health questionnaire 9 (PHQ-9) was the screening tool for depression. Minimal, mild, moderate, moderately severe and severe depression constituted the levels of depression in which participants with depressive symptoms felt. A score of nine and above $(\geq 9)$ was considered positive for depression. Further, the role of support groups were assessed through other questions that constituted the questionnaire and the activities carried out in support groups were observed and compared to standards of practice. Analysis revealed that $29.61 \%$ (95\% CI: $22.5 \%$ - 35.7\%) were positive for depression, and 108 (71.06\%) participants presented with depressive symptoms. The role of support groups to participants was that it helps them in adhering to medication, filling hopeful and aiding them in disclosing their seropositive status to family members. The student $t$-test: $t(70, \mathrm{~N}=71)=-0.468, p=$ 0.641 , showed no significant difference amongst support groups attendees
\end{abstract}


and non-attendees, however, they are important to PLHIV and its practice at the level of Bambui District Hospital should be improved.

\section{Keywords}

Depression, HIV, Support Groups, Bamenda

\section{Introduction}

Depression is a common mental disorder (CMD) manifested by low mood, loss of interest or pleasure, disturbed sleep or appetite, feelings of guilt or low self-worth, low energy and trouble concentrating. Depression is common and affecting more than 300 million people worldwide (WHO, 2017). Global studies have shown a wide variation in the prevalence of depression, but overall this prevalence is approximately $10 \%$ in general populations (Andrade et al., 2003; Stein et al., 2008; Herman et al., 2009). Evidence from these studies went further to highlights that there is nearly twofold increased prevalence of depression in people living with HIV (PLHIV), compared to the general population (Ciesla \& Roberts, 2001; Bing et al., 2001).The combination of these two common illnesses has profound consequences because of a significant impact on the person living with HIV and AIDS and, in to a greater extent healthcare systems. As a matter of fact, Cameroon has the largest HIV/AIDS epidemic in sub-region of Africa with an estimated HIV prevalence of 5.3\%, 610,000 people living with HIV, with 48,000 adults newly infected and 37,000 AIDS related deaths reported in 2009 (UNAIDS, 2010). Recent findings have shown that persons with depressed mood are more likely to engage in high-risk sexual behaviour (Gore-Felton \& Koopman, 2002), and could also lead to non-adherence to HAART, higher risk for co-morbid disorders and premature death (Farinpour et al., 2003; Cook et al., 2004; Horberg et al., 2008). Consequently, failure to recognize and treat depression endangers not only the patient, but the community as well. It is therefore primordial to early identify depression prior to its management, unfortunately in Cameroon, the management of HIV/AIDS emphasizes on somatic aspects of the disease and neglects psychiatric manifestations, and depression is therefore under diagnosed. This is essentially due to the fact that mental health services are not effectively integrated into HIV/AIDS clinical care (L'akoa et al., 2013).

Depressive tendencies are reduced if the patient's condition is known and accepted by the patient's family and when he involves himself in gratifying activities which could be professional, social or otherwise. On the other hand, risks for depression among HIV/AIDS patients increase when recent affective losses occur (death or rejection of all sorts), an accelerated evolution of opportunistic infections, increasing rate of hospitalizations; its duration as well as physical deterioration. Furthermore, in patients with HIV disease, severity of depression correlates with rapidity of decline in CD4 count, suggesting that failure to treat de- 
pression may accelerate HIV disease progression and impact on survival (Ross, 2004).

With HIV being a chronic disease, people living with HIV (PLHIV) face a lot of challenges such as, adherence to medication, poor nutrition, withstanding medication side effects, lack of support from family members, just to name a few, stigma. People facing similar conditions, especially unpleasant ones often find comfort, support and strength in being together with people in the same situation like them. Hence support groups can help reduce level of depression or prevent PLHIV at risk from developing it. Ndu et al. (2011) who conducted a study on; role of support groups in managing depression in Nigeria concluded that, being part of a support group turn to reduce the level of depression among PLHIV.

\section{Methodology}

\subsection{Participants Selection and Data Collection}

Given that the participants receive a health talk each morning before receiving their ARVs, during this period, informed consent was obtained before randomly distributing the questionnaires. This was also done with the help of the ward charge who assisted in obtaining informed consent. This was of great help to the researcher since the participants easily listen to him and readily obeys his instructions.

A simple random sampling technique was used to select participants wherein questionnaires were shared without following a specific rule in the hall. Out of nearly 100 participants on daily basis, ten to fifteen participants were selected at random. The researcher then proceeded by administering questionnaire when respondents were not reluctant nor rejected the opportunity to take part in the investigation. This was performed when they were waiting to collect drugs at the level of the pharmacy or when their files were being updated. The participants were addressed in English and "Pigin". Those who could self-administer answer the questionnaires on their own were allowed to answer, while those who were willing to participate but could not read were interviewed and responses documented against their coded questionnaire. Support group meetings were attended all Saturdays and data collected through by answering questions stipulated in the observational guide.

\subsection{Data Analysis}

Data from questionnaires were coded on Microsoft Excel and then, coded data was forwarded to IBM SPSS Version 21 for analysis. Data were presented in charts and tables following the order of the research objectives. Means and standard deviation were the main measures of central tendencies. Depression scores were compared using the student $t$-test to test for a significant difference. The chi-square test $\left(x^{2}\right)$ was used were appropriate to test for association or independence between categorical variables. P-values below $0.05(p<0.05)$ were considered statistically significant at $95 \%$ confidence interval. 


\subsection{Scoring and Interpretation}

Pfizer and associates have suggested the use of a simpler proxy system of scoring to estimate diagnostic categories. This site includes also information concerning making a tentative diagnosis, a guide for severity scoring, a provisional diagnosis table, and a treatment response table for primary care clinicians. The maximum score is 27 (9 questions $x$ maximum 3 points per question). A patient's score is given out of 27. Depression severity is graded based on the PHQ-9 score as in Table 1 below.

\subsection{Validity and Reliability of Research Tool}

The PHQ-9 has been tested for validity and reliability in a range of languages. It has been validated also for use in a variety of populations, e.g. systematic sclerosis, depression in HIV/AIDs patients, and depression in diabetes patients. A PHQ-9 score of greater than 9 has a sensitivity of $83 \%$ and a specificity of $92 \%$ for major depressive disorder diagnosis (Kroenke et al., 2001). In this study, a positive depression screen was defined as PHQ-9 score greater than or equal to nine ( $\geq 9)$.

\subsection{Ethical Consideration}

The consent of all participants was obtained before administering any questionnaires. The responses of all participants were kept confidential and their identity anonymous.

Moreover, a research clearance was obtained from the school administration and the regional delegation of health for the research to begging. At the level of the research area, authorization to start data collection is given by the director of the BRH and the General Supervisor. Furthermore, at the level of the research population, consent to start data collection was obtained by presentation of all ethical forms to the ward charge.

\section{Results}

\subsection{Awareness and Attendance of Support Groups}

Table 2 reveals that amongst participants who were aware of the existence of support groups 143 (94.7\%), the majority were non attendees 73 (48.3\%) while

Table 1. PHQ-9 grading Scale of different levels of depression.

\begin{tabular}{cc}
\hline Total Score & Depression Severity \\
\hline $1-4$ & Minimal depression \\
$5-9$ & Mild depression \\
$10-14$ & Moderate depression \\
$15-19$ & Moderately severe depression \\
$20-27$ & Severe depression \\
\hline
\end{tabular}

Kroenke K, Linzer M, deGruy FV, Hahn SR, et al. Utility of a new procedure for diagnosing mental disorders in primary care: the PRIME-MD 1000 study. JAMA. 1994; 272: 1749-1756. 
Table 2. Crosstable of awareness of PLHIV towards existence of support groups with respect their attendance to these groups.

\begin{tabular}{|c|c|c|c|c|c|}
\hline \multirow[b]{2}{*}{ Characteristic } & & \multicolumn{2}{|c|}{ Attendance to Support Groups } & \multirow{2}{*}{$\begin{array}{c}\text { Total } \\
\mathrm{n}(\mathrm{n} \%)\end{array}$} & \multirow[b]{2}{*}{ Statistic } \\
\hline & & $\begin{array}{c}\text { Number } \\
\text { of Attendees }\end{array}$ & $\begin{array}{c}\text { Number of } \\
\text { Non-Attendees }\end{array}$ & & \\
\hline \multirow{2}{*}{$\begin{array}{c}\text { Aware about existence } \\
\text { of support groups }\end{array}$} & $\mathrm{n}$ & 70 & 73 & 143 & \multirow{6}{*}{$\begin{array}{l}p=0.007 \\
\chi^{2}=7.300\end{array}$} \\
\hline & $\%$ & $46.4 \%$ & $48.3 \%$ & $94.7 \%$ & \\
\hline \multirow{2}{*}{$\begin{array}{l}\text { Not aware of the existence } \\
\text { of support groups }\end{array}$} & $\mathrm{n}$ & 0 & 9 & 8 & \\
\hline & $\%$ & $0.0 \%$ & $5.3 \%$ & $5.3 \%$ & \\
\hline \multirow{2}{*}{ Total } & $\mathrm{n}$ & 70 & 82 & 152 & \\
\hline & $\%$ & $46.4 \%$ & $53.6 \%$ & $100.0 \%$ & \\
\hline
\end{tabular}

$\mathrm{n} \%=$ percentage of cases, $\mathrm{n}=$ number of cases, $\chi^{2}=$ chi-square statistic $\mathrm{p}=$ probability value.

those who were non attendees of support groups were nearly half of the whole distribution $70(46.4 \%)$. On the other hand, 9 (5.3\%) of those who were not aware of the existence of support groups were all non-attendees. Nevertheless, the majority of participants 143 (94.7\%) were aware of the existence of support groups while only $8(5.3 \%)$ stated that they are not aware of any support group.

A chi-square test of association reveals that a significant relationship exists between being aware of the existence of support groups and being part of a support group. $\chi^{2}(1, \mathrm{~N}=152)=7.300, p=0.007$, and participants who are aware of support groups are more likely to get involved in support group sessions, $(\mathrm{OR}=$ 0.51, CI: 0.435 - 0.599).

Table 3 shows that, majority of participants $(\mathrm{n}=25,32.1 \%)$ are not part of support groups because of their personal preoccupations, followed by most participants feeling reluctant or uninterested to take part in support group $(\mathrm{n}=18$, $23,1 \%)$, together living far distances as a reason for non-attendance $(\mathrm{n}=13$, 16.7\%). Minorities stated that they were either not well sensitized on the role of support groups $(\mathrm{n}=6,7.7 \%)$ or had problems language barrier.

\subsection{Prevalence of Depression, and Depressive Symptoms among PLHIV}

Taking into consideration the diagnostic criteria of depression according to the PHQ-9, analysis portrayed in Figure 1 shows that, nearly a third of respondents $45(29.61 \%)$ where positive for depression and the rest of respondents were experiencing no, one or more depressive symptoms but could not be categorised as being positive. In addition to that, Figure 2 reveals that, participants who had no depressive symptoms were predominant 44 (28.95\%) with those suffering from minimal to mild depression just nearly equal. Moreover, those who suffered from severe depression 6 (3.95\%) were twice the number of those who experienced moderately severe depression $3(1.97 \%)$ while $23(15.13 \%)$ of the respondents were classified as moderately depressive.

Table 4 below demonstrates that the majority of participants reported the 


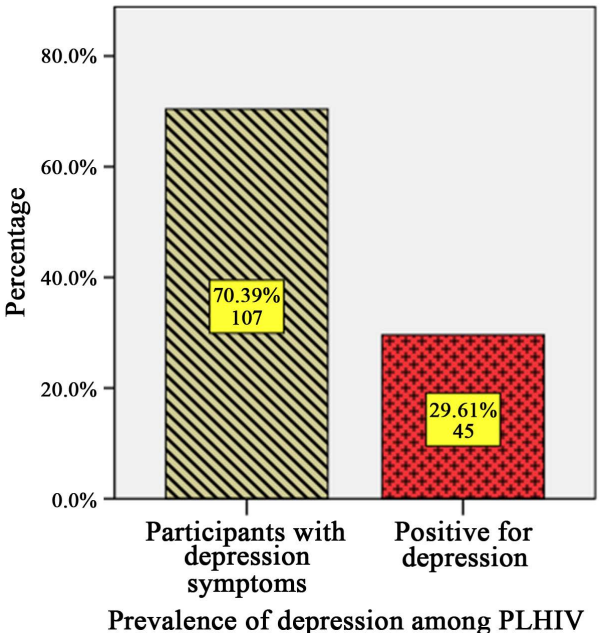

Figure 1. Prevalence of depression among participants.

Table 3. Reasons for not registering or not attending support groups.

\begin{tabular}{cccc}
\hline Characteristics & Categories of Responses Given by Participants & $\mathbf{n}$ & $\%$ \\
\hline & Living far/lack of transportation means & 13 & 16.7 \\
& Recently transferred to BRH or knew about SGs & 10 & 12.8 \\
$\begin{array}{c}\text { Reasons for } \\
\text { participants } \\
\text { for not } \\
\text { registering } \\
\begin{array}{c}\text { or attending } \\
\text { a support } \\
\text { groups }\end{array}\end{array}$ & Personal occupations/being busy or having no time & 25 & 32.1 \\
& Oeluctant/ not interested to register and participate & 18 & 23.1 \\
& Not well sensitized about support groups & 6 & 7.7 \\
& Do not understand English during & 1 & 1.3 \\
\hline
\end{tabular}

$\mathrm{n}=$ number of cases $\%=$ percentage of cases.

Table 4. Multiple response analysis of prevalence of depressive symptoms.

\begin{tabular}{|c|c|c|c|c|}
\hline & \multirow{2}{*}{ Depressive Symptoms } & \multicolumn{2}{|c|}{ Responses } & \multirow{2}{*}{ Percent of Cases } \\
\hline & & $\mathrm{N}$ & Percent & \\
\hline \multirow{10}{*}{$\begin{array}{l}\text { Prevalence } \\
\text { of depressive } \\
\text { symptoms }\end{array}$} & Feeling tired & 62 & $15.90 \%$ & $57.40 \%$ \\
\hline & Lack of sleep & 57 & $14.60 \%$ & $52.80 \%$ \\
\hline & Forgetful and restless & 55 & $14.10 \%$ & $50.90 \%$ \\
\hline & Anhedonia & 47 & $12.10 \%$ & $43.50 \%$ \\
\hline & Lack of appetite & 46 & $11.80 \%$ & $42.60 \%$ \\
\hline & Self-worthlessness & 41 & $10.50 \%$ & $38.00 \%$ \\
\hline & Sadness and feeling down & 39 & $10.00 \%$ & $36.10 \%$ \\
\hline & Lack of concentration & 33 & $8.50 \%$ & $30.60 \%$ \\
\hline & Suicide idea and thought of death & 10 & $2.60 \%$ & $9.30 \%$ \\
\hline & Total & 390 & $100.0 \%$ & $361.1 \%$ \\
\hline
\end{tabular}

$\mathrm{N}=$ number of respondents. 


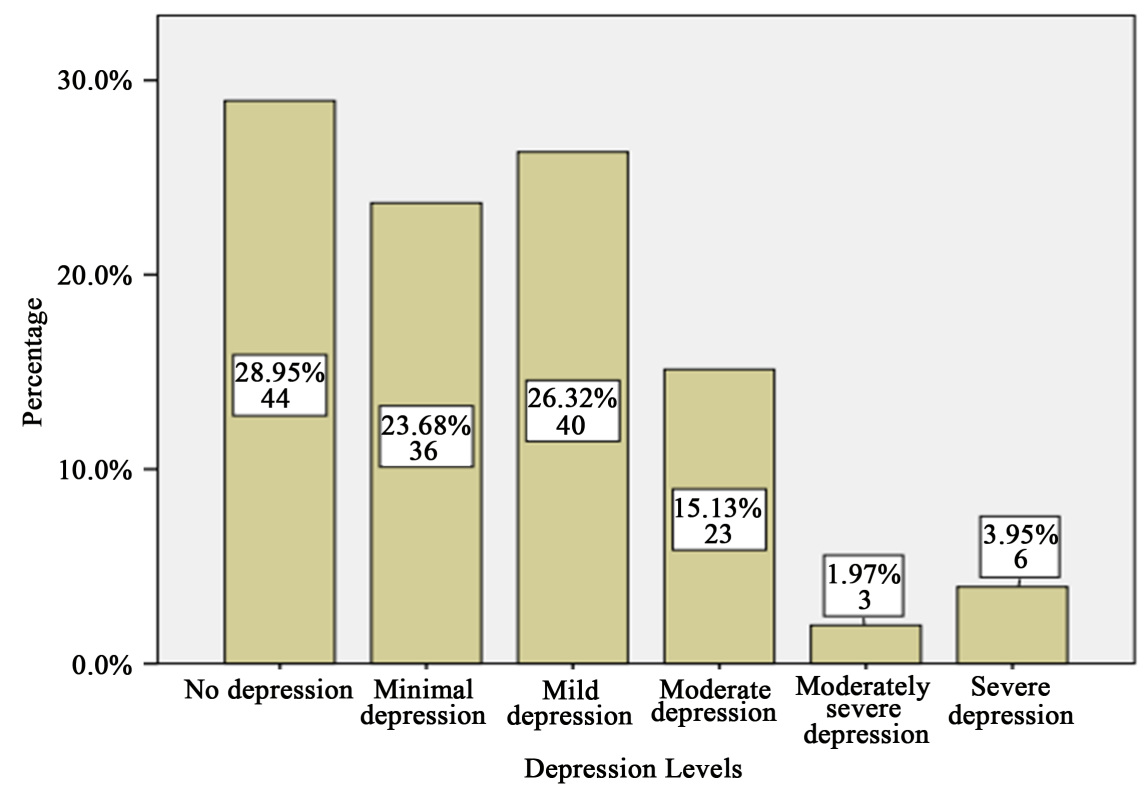

Figure 2. Depression levels among participants.

feeling of being tired as the main symptom of depression that recognised 62 (15.90\%) followed by insomnia $57(16.4 \%)$ and forgetfulness/restlessness 55 (14.10). Moreover, $10(2.6 \%)$ cases of the participants had suicide ideas or thought of death.

Table 5 shows that participants who were part of support groups had a mean depression level of 5.21 ( $\mathrm{SD}=5.634$ ) while those who were not part of support groups had a mean depression score of $5.62(\mathrm{SD}=5.533)$ corresponding to minimal depression in both cases. A student $t$ test for paired samples showed no significant difference between the two groups; $t(70, \mathrm{~N}=71)=-0.468, p=0.641$ however, support attendees were 0.732 times less likely to be depressed compared to non-attendees, $(\mathrm{OR}=0.732, \mathrm{CI}$ : 0.262 - 2.046), and participants who were not part of support groups (non-attendees) were 0.814 times more likely to become depressive (OR $=0.814$, CI: $0.409-1.620)$.

\subsection{Role of Support Groups}

Table 6 shows that promotion of adherence to ARVs was the predominant role of support groups $22(22.4 \%)$, followed by support groups aiding in enhancing hopefulness amongst participants 19 (19.4\%) and assisting clients in disclosure of their seropositive status 13 (11.4\%). However, among the participants who were part of the support groups114 (100.0\%), 14 (12.3\%) stated that though they are registered into support groups, they have never attended any support group session. Moreover, 6 (6.1\%) participants sees' support groups not to be helpful in any way to them.

Missing cases 38 (25\%) corresponding to participants who are not part of support groups or were part of support groups but had never attended one session. 
Table 5. Comparism of depression scores of support groups attendees and non-attendees.

\begin{tabular}{ccc}
\hline Categories $(\mathrm{N}=71)$ & Mean \pm SD & Statistics \\
\hline In support group & $5.21 \pm 5.634$ & $\mathrm{p}=0.641$ \\
Not in support group & $5.62 \pm 5.533$ & $t=-0.468 \mathrm{df}=70$ \\
\hline
\end{tabular}

$\mathrm{SD}=$ standard deviation, $\mathrm{N}=$ total number of sample pairs.

Table 6. Perceived role of support groups to participants.

\begin{tabular}{ccc}
\hline $\begin{array}{c}\text { Responses of the participants with regard to } \\
\text { how important support groups are to them }\end{array}$ & \multicolumn{2}{c}{ Responses } \\
\cline { 2 - 3 } It helps me take my drugs regularly without missing & $\mathrm{N}$ & $\%$ \\
\hline I have registered but never has attended a support group session & 22 & $22.40 \%$ \\
Give hope and the desire to live & 19 & $19.40 \%$ \\
\hline $\begin{array}{c}\text { It helps me talk about my status either with friends or family members } \\
\text { Help in learning of new behaviours, or coping skills }\end{array}$ & 13 & $14.30 \%$ \\
It is not really helpful in any way to me & 11 & $11.30 \%$ \\
It helps me not to feel stigmatise when & 6 & $6.10 \%$ \\
I see people like me who are doing well & 4 & $4.10 \%$ \\
Other roles of support groups & 3 & $3.10 \%$ \\
$\begin{array}{c}\text { Give education so as to know how to take care of } \\
\text { oneself at home (nutrition and hygiene education) }\end{array}$ & 2 & $2.02 \%$ \\
Listen to good stories related to defaulters and personal care & 2 & $2.02 \%$ \\
It helps me know that I have to practice protected sex & 1 & $1.02 \%$ \\
$\begin{array}{c}\text { Helps me develop my skills and provide me } \\
\text { with financial support (bingo support group) } \\
\text { Total }\end{array}$ & 1 & $1.02 \%$ \\
\hline
\end{tabular}

\subsection{Results of the Observation}

\section{See Table 7.}

\section{Discussion}

\subsection{Awareness/Attendance}

In relation to participants' awareness to support group existence, Table 2 revealed that 143 (94.7\%) respondents represented those who were aware of the existence of support groups while only $8(5.3 \%)$ stated that they were not aware of its existence. These results are consistent with a cross sectional quantitative study published by Madiba \& Canti-Sigaqa (2012) on barriers to participate in support groups by PLHIV in South African, where in a study of 248 PLHIV, just a few participants were unaware of support groups and the reason being that most participants tested for HIV at a the time when they were critically ill and did not remember what was said during counselling. In this current research, those who were unaware could correspond to participants who were newly diagnosed of HIV or who had problems in understanding English during lectures. 
Table 7. Results from observation of activities carried out at the level of support groups.

\begin{tabular}{lll}
\hline & No Components that Guided Observations & \multicolumn{2}{c}{ Support Groups under Observation } \\
\cline { 3 - 3 } & Bamenda Regional Hospital Support Group & Tubah District Hospital (BAMBUI)
\end{tabular}

Does the support group facilitate

1 mutual support among group members and reduce isolation?

Does the support group improve

2 social and family support/decrease feelings of loneliness and guilt?

Does it promote greater openness

3 and emotional expressiveness both within and outside the group?

Does the support group facilitate

4 integration of a changed self and body image into the patient's current view of self?

Does it improve coping skills and normalization of experiences?

6 Improve the doctor-patient Relationship?

Is there detoxification of feelings around death and dying in the support group?

8 Does it help patients develop a life project?

9

Does the support group promote safer sexual practices?

10

Does it enhance quality of life and greater authenticity?
YES, At the end of each session, participants coming from the same locality are made to know themselves, share phone contact and they are paired so as to serve as relay agents among themselves. Moreover, group members show willingness to share their personal problems which sometimes even proves to be complex or very intimate.

YES. Participants who even intend to get married are encouraged to come with their partners so that they can be help to disclose their status. Moreover, they are continuously enlightened on the importance of disclosing their status to close relative. This helps in relieving anxiety associated with reprisals of disclosing their status.

NO. Instead, participants are enlightened on adjustment patterns that can help them improve on their body image without making them to see the effects of HIV on their physical appearance.

YES. New coping skills are learned and enrich the spectrum of their existing coping skills. Their sources of inspiration lies on sharing of experiences observed from other members.

YES. Participants are reminded to always present the least complain related to their disease, side effects of ARVs or even opportunistic infection because any of them could proceed to a fatal complication.

YES. Even though the participants see other PLHIV dying, they are made to understand that death results mainly from defaulting, non-adherence, social isolation and depression.

More or less. Even though they are told that HIV is not the end and that it should not prevent them from proceeding with their normal activities, no participant was observed to be given the opportunity share his or her experience or on how he/she is succeeding in business. Or other activity.

YES. They are encourage on the importance of abstinence, fidelity and use of condom, and are cautioned on how resistance to HAART develops when unsafe sexual practice is carried out.

YES. PLHIV are encouraged to use the time with which they are left with to do valuable activities that can promote psychological, socioeconomic wellbeing.
YES, evidence by the fact that group members feel happy on observation when they meet together after one month of separation and surprisingly they are able to call each other by names despite their large numbers.

NO, even though the group decreases feeling of loneliness to an extent, activities here were mainly limited to sharing of ARVs.

NO. It should be noted that support group sessions that are done during the outreach at Tubah district hospital (Banbui) are done by archivist who are concerned with the management of patients' file at the regional hospital. They have no training related to health but handle the support group of Tubah based on routine practices and observations made at the level of BRH. Their main activity focus on encouraging patients to adhere to their ARVs, do their CD4 count and to identify those who are at potential risks.

Less or no time is was dedicated to discussion, but to activities that are normally performed during each clinic day when clients come for their normal visits such as registering patients and giving ARVs.

No education on safer sexual practices was observed.

No; no time was allocated so as to share with participants how they can valuably exploit their talents or abilities so as to improve on their quality of life. 
Looking in the same direction, we see that out of those who were aware of support group existence 143 (94.7\%), only 70 (46.4\%) were support group attendees. This result is inconsistent to that found by Kekana (2011) in an almost similar descriptive research on perceived barrier to participate to support groups by PLHIV in South Africa where, majority of participant (58.06\%) were instead non attendees. This difference may be accounted by the fact that, having most participants as literate, they face a lot of concern with their privacy, while in our context they instead have an unexplainable reluctance to participate. Going in the same line, a strong evidence of association between awareness and participation into support groups existed $\chi^{2}=7.300, p=0.007$, where participants who were aware of support groups were 0.5 times more likely to take part into support groups ( $\mathrm{OR}=0.51, \mathrm{CI}: 0.435-0.599)$. Madiba \& Canti-Sigaqa (2012) reported in a qualitative study with men receiving ART in a HIV Clinic in Mthatha, South Africa that participants who were aware of support groups perceived support groups as valuable to PLHIV.

\subsection{Prevalence of Depression}

Using the PHQ-9 as diagnostic tool for depression, the results of the study reveals an overall mean depression score of $5.41(\mathrm{SD}=5.55)$. Following this, it was found that 45 (29.61\%) (95\% CI: $22.5 \%$ - 35.7\%) were positive for depression. Nevertheless, Table 4 portrays that participants presented with depressive symptoms such as feeling tired 62 (57.4\%), lack of sleep 57 (52.8\%), forgetfulness and restlessness 55 (50.9\%), anhedonia 47 (43.5\%). This result is consistent with that obtained by l'Akoa et al., (2013) in an observational cross sectional study in which he assessed the prevalence of depressive symptoms amongst 100 newly diagnosed HIV patients in Yaounde. He had an overall prevalence of $63 \%$ of participants with depressive symptoms. Moreover, the current result is in line with that of Ndu et al. (2011) where in his cross sectional study, using the HADS; depression was prevalent by $21.3 \%$ among PLHIV. This variation in results for different researchers could be attributed to the fact that different depression assessment scales are used.

Figure 2 also revealed that, mild depression was the most dominant level 40 (26.32\%) followed by mnimal depression 36 (23.68\%). This is not in line with the cross sectional descriptive results obtained by Shittu et al. (2013) were most participants were instead affected by minimal depression (36.3\%). In his context, $4(13 \%)$ were severely depressive compared to $6(3.95 \%)$ in the current research. A difference of only two participants existed between severe and moderate depression in this current study. This inconsistence could arise from either the difference in sample size, length on which participants had been on ART, time at which they were diagnosed with HIV or how integrated mental health services exploited in both contexts. At the level of BRH, the only psychiatrist that was available recently went on retirement and the hospital has no psychiatrist on duty to help those who present with severe symptoms of depression, which con- 
firms the statements of l'Akoa et al. (2013) on the fact that mental health services are not integral part of follow up of PLHIV in Cameroon.

In addition, feeling tired or lack of energy 62 (15.9\%) was the most depressive symptom followed by insomnia $57(14.6 \%)$ with the least being suicide ideation or preferring death $10(2.6 \%)$ as shown in Table 4 . These results are inconsistent with that obtained by Gaynes et al. (2012) who assessed the epidemiology of depression among HIV patients at BRH. In his descriptive study, any form of insomnia $29(100.0 \%)$ was predominant followed by anhedonia 28 (97\%). This difference is probably related to the use of the World Health Organization's Composite International Diagnostic Instrument (CIDI) which gives details on severity, impairment, service use, and treatment, and has improved generalizability with increased involvement of less wealthy countries (Sikkema, 2011). Given the effects of HIV infection on physical symptoms such as fatigue, weight loss and sleep disturbance, it may be difficult for clinicians to disentangle the extent to which such symptoms result from the illness itself or depression. In one study, the elimination of somatic items from two depression rating scales improved their usefulness (Kalichman et al., 2000) and in other contexts such as the evaluation of the elderly or medically ill similar strategies has been helpful. The risk of de-emphasizing the impact of depression on physical symptoms creates the possibility that some cases of depression may not be identified (Ownby et al., 2009).

\subsection{Role of Support Group}

As earlier seen in Table 3, it was observed that most respondents were not attending support groups mainly because they had personal occupations or being busy $25(32.1 \%)$. Another important reason to note was reluctance to participate $18(21.3 \%)$, or having a residence far from the support group site $13(16.7 \%)$. This result is incoherent with that obtained by Kekana (2011) in a descriptive study and, Madiba \& Canti-Sigaqa (2012) in a cross sectional quantitative studies in which participants were instead concerned with large support group size and their privacy. This contrast could be related to the difference in literacy level in both studies. However, Canti-Sigaqa (2010) had contradictory findings in which he reports that participants were reluctant to attend support groups for fear of being recognized. They felt that participating in support group in their communities is like disclosing their HIV status and most did not want their status to be known by people in their communities because of stigma and social rejection.

In relation to the role of support groups, Table 6 showed that most participants who were part of support groups stated that; it helps them in adhering to their treatment $22(22.4 \%)$ while some attendees were not seeing support groups to be helpful in any way $6(6.1 \%)$. Pass literature on how support groups are important to PLHIV is extremely rare and this makes the current research unique. Nevertheless, a cross sectional descriptive research conducted by $\mathrm{Ndu}$ et 
al. (2011) in Nigeria on a similar topic does not tell us how helpful support groups are to PLHIV, but instead goes to the extent of compare the level of depression of participants who are in support groups and, those who are non-attendees and at the end, he draw a conclusion on how important support groups could be to PLHIV. Furthermore, no assessment was done to find why some attendees of support groups perceived activities of support groups not to be important or helpful to them in any way, hence reveals a limitation of the study.

Moreover, in comparing the mean depression scores between participants in support groups and those that are not, Table 5 showed that participants who were part of support groups had a mean depression level of $5.21(\mathrm{SD}=5.634)$ while those who were not part of support groups had a mean depression score of $5.62(\mathrm{SD}=5.533)$ corresponding to minimal depression in both cases. A student $t$ test for paired samples showed no significant difference between the two groups; $t(70, \mathrm{~N}=71)=-0.468, \mathrm{p}=0.64$. Even though $\mathrm{Ndu}$ et al. (2011) used a different assessment scale in his cross sectional study, this finding was similar to that obtained by his research in that no significant difference relative to the depressive level of participants was found between those who were in support groups and those who were not $\left(\chi^{2}=1.40, P=0.236\right)$. Even though no mean difference exists, participants who are in support groups are 0.732 times less likely to be depressed ( $\mathrm{OR}=0.732$, CI: $0.262-2.046)$.

\section{Limitation}

This research did not do a logistic regression analysis to determine whether depressive symptoms were due to the fact that participants were not part of support groups or due to adverse effects of antiretroviral therapy, hence a problem from confounding.

Support groups in Cameroon are still emerging and in their genesis, so their efficiency in helping depressed individuals should not be over expected and therefore needs further assessment so as to accept their credibility.

Reasons why support group attendees stated that it is of no help to them were not assessed in this research; hence further assessment will mitigate this limitation.

Language barrier and illiteracy was a capital challenge in gathering information from participants since the components of the PHQ-9 needed some cognitive efforts for those who self-administered the questionnaire and understanding for those who were interviewed. In using down to earth language with illiterate participants, reliability of the responses is altered compared to when participants provide answers to questions themselves.

\section{Conflicts of Interest}

The authors declare no conflicts of interest regarding the publication of this paper. 


\section{References}

Andrade, L., Caraveo-Anduaga, J. J., Berglund, P., Bijl, R. V., De Graaf, R., Vollebergh, W., et al. (2003). The Epidemiology of Major Depressive Episodes: Results from the International Consortium of Psychiatric Epidemiology (ICPE) Surveys. International Journal of Methods in Psychiatric Research, 12, 3-21. https://doi.org/10.1002/mpr.138

Bing, E. G., Burnam, M. A., Longshore, D., Fleishman, J. A., Sherbourne, C. D., London A. S., et al. (2001). Psychiatric Disorders and Drug Use among Human Immunodeficiency Virus-Infected Adults in the United States. Arch Gen Psychiatry, 58, 721-728. https://doi.org/10.1001/archpsyc.58.8.721

Canti-Sigaqa, V. (2010). Non-Participation of HIV Positive Men in Support Groups for People Living with HIV/AIDS in the King Sabata Dalindyebo (KSD) Municipality: Eastern Cape Province; an Exploratory Study. Polokwane: University of Limpopo (Medunsa Campus).

Ciesla, J. A., \& Roberts, J. E. (2001). Meta-Analysis of the Relationship between HIV Infection and Risk for Depressive Disorders. The American Journal of Psychiatry, 158, 725-730. https://doi.org/10.1176/appi.ajp.158.5.725

Cook, J. A., Grey, D., Burke, J., Cohen, M. H., Gurtman, A. C., Richardson, J. L., Wilson, T. E., Young, M. A., \& Hessol, N. A. (2004). Depressive Symptoms and AIDS-Related among a Multisite Cohort of HIV-Positive Women. American Journal of Public Health, 94, 133-1140. https://doi.org/10.2105/AJPH.94.7.1133

Farinpour, R., Miller, E. N., Satz, P., Selnes, O. A., Cohen, B. A., Becker, J. T., Skolasky, R. L., \& Visscher, B. R. (2003). Psychosocial Risk Factors of HIV Morbidity and Mortality: Findings from the Multicenter AIDS Cohort Study (MACS). Journal of Clinical and Experimental Neuropsychology, 25, 654-670.

https://doi.org/10.1076/jcen.25.5.654.14577

Gaynes, B. N., Pence, B. W., Atashili, J., O’Donnell, J., Kats, D. et al. (2012). Prevalence and Predictors of Major Depression in HIV-Infected Patients on Antiretroviral Therapy in Bamenda, a Semi-Urban Center in Cameroon. PLoS ONE, 7, e41699.

https://doi.org/10.1371/journal.pone.0041699

Gore-Felton, C., \& Koopman, C. (2002). Traumatic Experiences: Harbinger of Risk Behavior among HIV Positive Adults. Journal of Trauma \& Dissociation, 3, 121-135. https://doi.org/10.1300/J229v03n04_07

Herman, A. A., Stein, D. J., Seedat, S., Heeringa, S. G., Moomal, H., \& Williams, D. R. (2009). The South African Stress and Health (SASH) Study: 12-Month and Lifetime Prevalence of Common Mental Disorders. The South African Medical Journal, 99, 339-344.

Horberg, M. A., Silverberg, M. J., Hurley, B. L., Towner, W. J., Klein, D. B., BersoffMatcha, S., Weinberg, W. G., Antoniskis, D., Mogyoros, M., Dodge, W. T., Dobrinich, R., Quesenberry, C. P., \& Kovach, D. A. (2008). Effects of Depression and Selective Serotonin Reuptake Inhibitor Use on Adherence to Highly Active Antiretroviral Therapy and on Clinical Outcomes in HIV-Infected Patients. JAIDS Journal of Acquired Immune Deficiency Syndromes, 47, 384-390. https://doi.org/10.1097/QAI.0b013e318160d53e

Kalichman, S. C., Rompa, D., \& Cage, M. (2000). Distinguishing between Overlapping Somatic Symptoms of Depression and HIV Disease in People Living with HIV-AIDS. The Journal of Nervous and Mental Disease, 188, 662-670. https://doi.org/10.1097/00005053-200010000-00004

Kekana, M. O. (2011). Perceived Barriers to Participation in HIV Support Groups among People Living with HIV and AIDS at Katlehong Township-South Africa. 
Kroenke, K., Linzer, M., deGruy, F. V., Hahn, S. R. et al. (1994). Utility of a New Procedure for Diagnosing Mental Disorders in Primary Care: The PRIME-MD 1000 Study. JAMA, 272, 1749-1756. https://doi.org/10.1001/jama.1994.03520220043029

Kroenke, K., Spitzer, R. L., \& Williams, J. B. (2001). The PHQ-9: Validity of a Brief Depression Severity Measure. Journal of General Internal Medicine, 16, 606-613. https://doi.org/10.1046/j.1525-1497.2001.016009606.x

L'akoa, R. M., Noubiap, J. J. N., Yixin, F., Ntone, F. E., \& Christopher, K. (2013). Prevalence and Correlates of Depressive Symptoms in HIV-Positive Patients: A Cross-Sectional Study among Newly Diagnosed Patients in Yaoundé, Cameroon. Biomed Central Psychiatry, 13, 228. https://doi.org/10.1186/1471-244X-13-228

Madiba, S., \& Canti-Sigaqa, V. (2012). Barriers to Participate in Support Groups for People Living with HIV: A Qualitative Study with Men Receiving Antiretroviral Treatment in a HIV Clinic in Mthatha, South Africa. Global Journal of Health Science, 4, 119-120. https://doi.org/10.5539/gjhs.v4n6p119

Ndu, A. C., Arinze, S. U., Aguwa, E. N., \& Obio, I. E. (2011). Prevalence of Depression and Role of Support Group in Its Management: A Study of Adult HIV/AIDS Patients Attending HIV/AIDS Clinic in a Tertiary Health Facility in South-Eastern Nigeria. Journal of Public Health and Epidemiology, 3, 182-186.

Ownby, R. L., Kumar, A. M., \& Benny, F. J. (2009). Tumor Necrosis Factor-Alpha Levels in HIV-1 Seropositive Injecting Drug Users. Journal of Neuroimmune Pharmacology, 4, 350-358. https://doi.org/10.1007/s11481-009-9150-x

Ross, S. (2004). The Diagnosis and Treatment of Depression in HIV Infected People. HIV Treatment Series II: Part Four of Four.

Shittu, R. O., Issa, B. A., Olanrewaju, G. T., Mahmoud, A. O., Odeigah, L. O. et al. (2013). Prevalence and Correlates of Depressive Disorders among People Living with HIV/AIDS, in North Central Nigeria. Journal of AIDS and Clinical Research, 4, 251. https://doi.org/10.4172/2155-6113.1000251

Sikkema, K. J., Watt, M. H., Meade, C. S., Ranby, K. W., \& Kalichman, S. C. (2011). Mental Health and HIV Sexual Risk Behavior among Patrons of Alcohol Serving Venues in Cape Town, South Africa. Journal of Acquired Immune Deficiency Syndromes, 57, 230-237. https://doi.org/10.1097/QAI.0b013e3182167e7a

Stein, D. J., Seedat, S., Herman, A., Moomal, H., Heeringa, S. G., Kessler, R. C., et al. (2008). Lifetime Prevalence of Psychiatric Disorders in South Africa. The British Journal of Psychiatry, 192, 112-117. https://doi.org/10.1192/bjp.bp.106.029280

UNAIDS (2010). UNAIDS Report on the Global AIDS Epidemic 2010. http://www.unaids.org/documents/20101123_globalreport_em.pdfwebcite

World Health Organization (2017). Media Centre. Depression Facts Sheet. http://www.who.int/mediacentre/factsheets/fs369/en/ 